\title{
A New Species of the Acanthocephalan Genus Filisoma (Cavisomidae) from Perciform Fishes in Rio de Janeiro, Brasil
}

\author{
Viviane S. Costa Fernandes ${ }^{1} \cdot$ Omar Amin ${ }^{2}$. Juliana N. Borges ${ }^{1} \cdot$ Cláudia P. Santos $^{1}$
}

Received: 25 June 2018 / Accepted: 11 December 2018 / Published online: 11 February 2019

(C) The Author(s) 2019

\begin{abstract}
Background Twelve species of Filisoma Van Cleave, 1928 are recognized parasitizing tropical and subtropical fish. Four of these species were described from kyphosid fish and it has been suggested that a co-speciation may have occurred among species of Kyphosus Lacepède, 1801 and Filisoma, which could provide valuable information about the evolution history of this host-parasite system.

Purpose During a survey of the helminth fauna of Kyphosus sectatrix (Linnaeus, 1758) and Kyphosus incisor (Cuvier, 1831) (Kyphosidae Jordan, 1887) off Rio de Janeiro coast, a new species of Filisoma was found and is described herein based on morphological, genetic, and ultrastructural data.

Methods Fish were obtained off Rio de Janeiro coast, Brazil. The parasites found in the intestine were measured and drawings were made with a drawing tube. Type specimens were deposited at the Helminthological Collection of Oswaldo Cruz Institute (CHIOC). The ultrastructure was studied using scanning electron microscope. The genetic analysis included the study of the partial sequences of 18S, ITS1, 5.8S and 28S rDNA, and the mitochondrial cytochrome c oxidase 1 gene (cox 1), with phylogenetic reconstructions based on the maximum likelihood analysis.

Results Filisoma caudata n. sp. is characterized by a proboscis with 16-18 longitudinal rows of 38-45 hooks each. Hooks are uniform in shape dorsoventrally, gradually decreasing in size towards the base of the proboscis. Anterior hooks are 30-45 $\mu$ long, middle hooks 30-35 $\mu$ long and 5 basal transversal hooks 20-30 $\mu$ long. The new species is differentiated from the closest species Filisoma filiformis Weaver and Smales, 2013 by the size and distribution of hooks, apart from having a subterminal vulva and a curved posterior trunk end (tail) measuring 500-1,000 long. Phylogenetic analysis based on 18S, 28S rDNA and mtDNA-cox 1 markers grouped the new species with Filisoma bucerium Van Cleave, 1940 and Filisoma rizalinum Tubangui and Masiluñgan, 1946 showing a close relationship between these species of Cavisomidae Meyer, 1932 and Echinorhynchidae Cobbold, 1879; the latter represented by species of Acanthocephalus Koelreuther, 1771. The new species can be differentiated from others on morphological and molecular basis. A key to the 13 species of Filisoma Van Cleave, 1928 is provided.

Conclusion Filisoma caudata n. sp. is described herein based on morphological, genetic, and ultrastructural data. The topologies of obtained phylogenies suggest that species of Echinorhynchidae should be reevaluated since the family is considered paraphyletic in all analyses conducted.
\end{abstract}

Keywords Acanthocephala $\cdot$ Filisoma caudata n. sp. $\cdot$ Fish $\cdot$ Kyphosus $\cdot$ Systematic $\cdot$ Taxonomy

\section{Introduction}

Acanthocephalans of the genus Filisoma Van Cleave, 1928 have been described from fish from tropical and subtropical waters, including species of the family Kyphosidae Jordan,

Cláudia P. Santos

cpsantos@ioc.fiocruz.br; portesclaudia@gmail.com

Extended author information available on the last page of the article
$1887[1,2]$. Twelve species are recognized within the genus [3] including the type species Filisoma bucerium Van Cleave, 1940; F. acanthocybii Wang, Wang \& Wu, 1993; F. atropi Wang, 1988; Filisoma fidum Van Cleave \& Manter 1947; Filisoma filiformis Weaver and Smales 2013; F. indicum Van Cleave, 1928; F. inglisi Gupta \& Naqvi, 1984; F. longcementglandatus Amin \& Nahhas, 1994; F. micracanthi Harada, 1938; F. oplegnathi Wang, 1988; Filisoma 
rizalinum Tubangui \& Masiluñgan, 1946 and F. scatophagusi Datta \& Soota, 1962 (see especially $[2,4,5]$ ).

Four of these species were described from kyphosid fish and it has been suggested that a co-speciation may have occurred among species of Kyphosus Lacepède, 1801 and Filisoma which could provide valuable information about the evolution history of this host-parasite system $[1,6,7]$. Although studies that use the integrative taxonomy (using different tools that includes morphological, ultrastructural, biochemical, molecular, and behavioral studies to delimit and characterize species) have been increasing in the last few years [8], the number of studies using this approach is still scarce $[9,10])$.

During a survey of the helminth fauna of Kyphosus sectatrix (Linnaeus, 1758) and Kyphosus incisor (Cuvier, 1831) off Rio de Janeiro coast, a new species of Filisoma was found and is described herein based on morphological, genetic, and ultrastructural data.

\section{Materials and Methods}

\section{Ethical Statement}

Collections in this study were authorized by the Brazilian Institute of Environment and Renewable Natural Resources (IBAMA, license no. 15898-1).

\section{Fish Collection}

A total of 22 specimens of $K$. incisor were examined from October 2013 to March 2015; nine were acquired from fishermen of Copacabana beach $\left(22^{\circ} 59^{\prime} 08^{\prime \prime} \mathrm{S}, 43^{\circ} 11^{\prime} 18^{\prime \prime} \mathrm{W}\right)$ and 13 were obtained from local fish markets. The mean total length of fish was $46 \pm 5(35-53) \mathrm{cm}$ and mean weight was $1672 \pm 549(730-2370) \mathrm{g}$. Acanthocephalans from a single specimen of $K$. sectatrix measuring $30 \mathrm{~cm}$ long and weighing $525 \mathrm{~g}$, collected in 2005 at Ilha Grande Bay $\left(23^{\circ} 04^{\prime} 04.62^{\prime \prime} \mathrm{S}\right.$, $44^{\circ} 13^{\prime} 31.95^{\prime \prime} \mathrm{W}$ ) were also examined for comparison. Fish were identified according to Froese and Pauly [11].

\section{Light Microscopy}

The parasites found in the intestine were washed in physiological saline $(0.7 \%)$ and fixed in AFA, $4 \%$ formalin or $70 \%$ alcohol. Some acanthocephalans were stained with alcohol chloride carmine, cleared in clove oil and mounted in Canada balsam. Observations were based on the specimens collected from two hosts: $K$. incisor and $K$. sectatrix and measurements are given in micrometres, with range in parentheses, unless otherwise stated; holotype measurements are in brackets. Drawings were made with a drawing tube and redrawn using Adobe Illustrator CS6 [12]. The prevalence, intensity, mean intensity and mean abundance follow Bush et al. [13]. Specimens were deposited at the Helminthological Collection of Oswaldo Cruz Institute (CHIOC).

\section{Scanning Electron Microscopy (SEM)}

Specimens fixed in AFA or 4\% formalin were washed in $0.1 \mathrm{M} \mathrm{Na}$-cacodylate buffer, post-fixed for $40 \mathrm{~min}$ in a solution of $1 \%$ osmium tetroxide in $0.8 \%$ potassium ferrocyanide in $0.1 \mathrm{M} \mathrm{Na}$-cacodylate buffer, dehydrated in an ascending alcohol series, dried by the critical point method with $\mathrm{CO}_{2}$, and sputter-coated with gold $60 \mathrm{~nm}$. Samples were examined using a JEOL JSM 6390 LV scanning electron microscope (JEOL Ltd., Tokyo, Japan) at the Electron Microscopy Platform, Fundação Oswaldo Cruz.

\section{Genetic Analysis}

DNA was extracted using the phenol-chloroform method as described by Billings et al. [14] and a set of primers were used to amplify different regions of the DNA. The partial 28S rDNA gene was amplified by PCR using the primers C1 (5'-ACC CGC TGA ATT TAA GCA T-3') and D2 (5'TGG TCC GTG TTT CAA GAC-3') (Hassouna et al. [15], after Chisholm et al. [16]). For partial 18S, ITS1 and 5.8S, the primers S1 (5'-TTC CGA TAA CGA ACG AGA CT-3') and H7 (5'-GCT GCG TTC TTC ATC GAT ACT CG-3') [17] were used. For partial fragment of the mitochondrial cytochrome $c$ oxidase 1 gene (cox 1$)$ primers LCO (5'-GGT CAA CAA ATC ATA AAG ATA TTG G-3') and HCO (5'TAA ACT TCA GGG TGA CCA AAA AAT CA-3') [18] were used. PCR was carried out using cycling parameters as previously described by those authors. The PCR products were analyzed by electrophoresis in $1.5 \%$ agarose gels, stained with SyberGreen (Invitrogen, Eugene, Oregon, USA) and photographed under UV transillumination. Amplified PCR products were purified with ExoSap-IT PCR Product Cleanup (USB ${ }^{\circledR}$ Products Affymetrix Inc., Cleveland, Ohio, USA). DNA cycle sequencing reactions were performed using BigDye Terminator v.3.1 (Applied Biosystems, Foster City, CA, USA) and automated sequencing was done using the Sequencing Platform at the Fundacão Oswaldo Cruz-PDTIS/FIOCRUZ in Brasil. Sequences of both strands were edited and aligned using the MEGA version 7.0 software [19]. Sequences were compared to others available in the GenBank database using the BLASTN program from the National Center for Biotechnology Information (NCBI) server (http://www.ncbi.nlm.nih.gov/BLAST) [20]. The nucleotide sequences were aligned using the CLUSTAL W algorithm [21] of the MEGA 7.0 package. Maximum likelihood (ML) phylogenetic trees were inferred using the best-fit model of MEGA 7.0: the Kimura two parameters 
Table 1 GenBank sequences used in the phylogenetic analysis

\begin{tabular}{|c|c|c|c|}
\hline \multirow[t]{2}{*}{ Species } & \multicolumn{3}{|l|}{ Accession numbers } \\
\hline & 18S rDNA & 28S rDNA & mtDNA-coxl \\
\hline Filisoma caudata n.sp. & МН004442-МН004445 & $\begin{array}{l}\text { MH004455- } \\
\text { MH004456 }\end{array}$ & $\begin{array}{l}\text { MH004407- } \\
\text { MH004411/ } \\
\text { MH021180 }\end{array}$ \\
\hline Filisoma bucerium & AF064814 & AY829110 & DQ089722 \\
\hline Filisoma rizalinum & JX014229 & - & - \\
\hline Acanthocephalus dirus & AY830151 & - & DQ089718 \\
\hline Acanthocephalus lucii & AY830152 & KM656148 & AM039837/KP261016 \\
\hline Acanthocephalus nanus & - & LC100043 & - \\
\hline Acanthocephalus anguillae & - & - & AM039864 \\
\hline Acanthocephalus sp. & DQ147605 & - & - \\
\hline Pseudoacanthocephalus toshimai & LC129278 & - & - \\
\hline Pseudoacanthocephalus lucidus & LC129279 & LC100041 & - \\
\hline Pseudoacanthocephalus nguyenthileae & - & KC491890 & - \\
\hline Pseudoacanthocephalus bufonis & - & KC491878 & - \\
\hline Acanthocephaloides propinquus & AY830149 & - & - \\
\hline Echinorhynchus gadi & EF107643/EF107646 & - & KP261022 \\
\hline Echinorhynchus truttae & AY830156 & KM656147 & - \\
\hline Echinorhynchus brayi & - & KM656151 & KP261015 \\
\hline Rhadinorhynchus lintoni & JX014224 & - & - \\
\hline Rhadinorhynchus pristis & JX014226 & - & JQ061132 \\
\hline Pomphorhynchus tereticollis & AY423347 & - & - \\
\hline Pomphorhynchus laevis & JX014223 & - & - \\
\hline Macracanthorhynchus ingens & AF001844 & - & - \\
\hline Polyacanthorhynchus caballeroi & - & DQ089738 & DQ089724 \\
\hline
\end{tabular}

(K2P) with invariant site (I) for the $18 \mathrm{~S}$ rDNA and for $28 \mathrm{~S}$ rDNA and mtDNA cox-1 the Hasegawa-Kishino-Yano (HKY) model including estimates of invariant sites (I) and gamma distribution. The tree was resampled by 1000 bootstrap replicates to evaluate the reliability of the groups. The sequences of Filisoma caudata $\mathrm{n}$. sp were deposited in the GenBank as mtDNA cox-1 region accession numbers MH004408 and MH004410 (666 bp each); MH004409 and MH004411 (665 bp each); MH004407 (657 bp) and MH021180 (635 bp). The sequences for partial 18S rDNA included numbers MH004443 (723 bp), MH004443 (647 bp), MH004444 (651 bp) and MH004445 (453 bp). For partial 28S rDNA the accession numbers were MH004455 (670 bp) and MH004456 (513 bp). The sequences used for the phylogenetic analysis are listed in Table 1.

\section{Results}

Acanthocephala

Palaeacanthocephala Meyer, 1931

Echinorhynchida Southwell \& Macfie, 1925

Cavisomidae Meyer, 1932

Filisoma Van Cleave, 1928
Filisoma caudata n. sp.

Type host: K. incisor (Cuvier)

Other host: $K$. sectatrix (Linn.)

Site of infection: Intestine

Type locality: Copacabana Beach, Rio de Janeiro, Brasil $\left(22^{\circ} 59^{\prime} 08^{\prime \prime} \mathrm{S}, 43^{\circ} 11^{\prime} 18^{\prime \prime} \mathrm{W}\right)$

Other locality: Ilha Grande Bay (K. sectatrix), Rio de

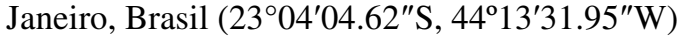

Specimens deposited: From K. incisor no. 39072 a-f (a-holotype, b-alotype, c-f paratypes), 39073 and 39075 a-b (vouchers). From K. sectatrix no. 39074 a-b (males) and $\mathrm{c}-\mathrm{d}$ (females).

Etymology: The new species is named as an adjective referring to the specific name of the host.

Nine of 22 examined specimens of $K$. incisor (41\%) were infected with 212 acanthocephalans in Copacabana Beach, Rio de Janeiro. Intensity was 4-87 with a mean intensity of $25 \pm 28$ and mean abundance: $10 \pm 21$. One specimen of $K$. sectatrix was also found heavily infected. The acanthocephalans were identified in the genus Filisoma Van Cleave, 1928 because of their long and slender unarmed trunk and proboscis with many hooks decreasing in size anteriorly and posteriorly, long lemnisci, double-walled proboscis receptacle with cephalic ganglion at its base, and four long tubular 
cement glands. A comparison with known species of Filisoma determined that it is new. This makes $F$. caudata $\mathrm{n}$. sp. the 13th valid species of the genus and the first to be described in South America. Species of Filisoma appears to be present in fishes inhabiting the tropical and semitropical waters of the Indo-pacific region. The hosts, $K$. incisor and $K$. sectatrix, are nektonic, forming schools in shallow waters associated with coral reefs, sand or rocky bottom. In Western Atlantic K. incisor occurs from the United States to Argentina while K. sectatrix occurs from Canada to Santa Catarina (Brasil). These species may also occur in Eastern Atlantic coasts of Spain and Africa. They are diurnal, feeding mainly on plankton, benthonic algae, detritus, small mollusks and crustaceans (Froese and Pauly [11]).

\section{Description}

General Cavisomidae, with characters of the genus Filisoma. Trunk whitish to light yellow, unarmed, long and slender (Fig. 1A). Females larger than males. Proboscis long, with 17 (16-18) longitudinal rows each with 42 (38-45) hooks (Figs. 1A-C, 2A, B). Proboscis hooks directed posteriorly, with simple roots smaller than blades. Hooks uniform in shape dorsoventrally (Fig. 1C) gradually decrease in size posteriorly and measure 35 (30-45) long anteriorly, 30
Fig. 1 Filisoma caudata n. sp. light microscopy drawing. A: Whole body of male. B: Proboscis. C: Hook at middle of proboscis. D: Male posterior end. E: Uterus, vagina and genital pore of female. F: Egg. A: $3 \mathrm{~mm}$; B-C: $100 \mu \mathrm{m}$; D-E: $500 \mu \mathrm{m} ; \mathbf{F}: 50 \mu \mathrm{m}$

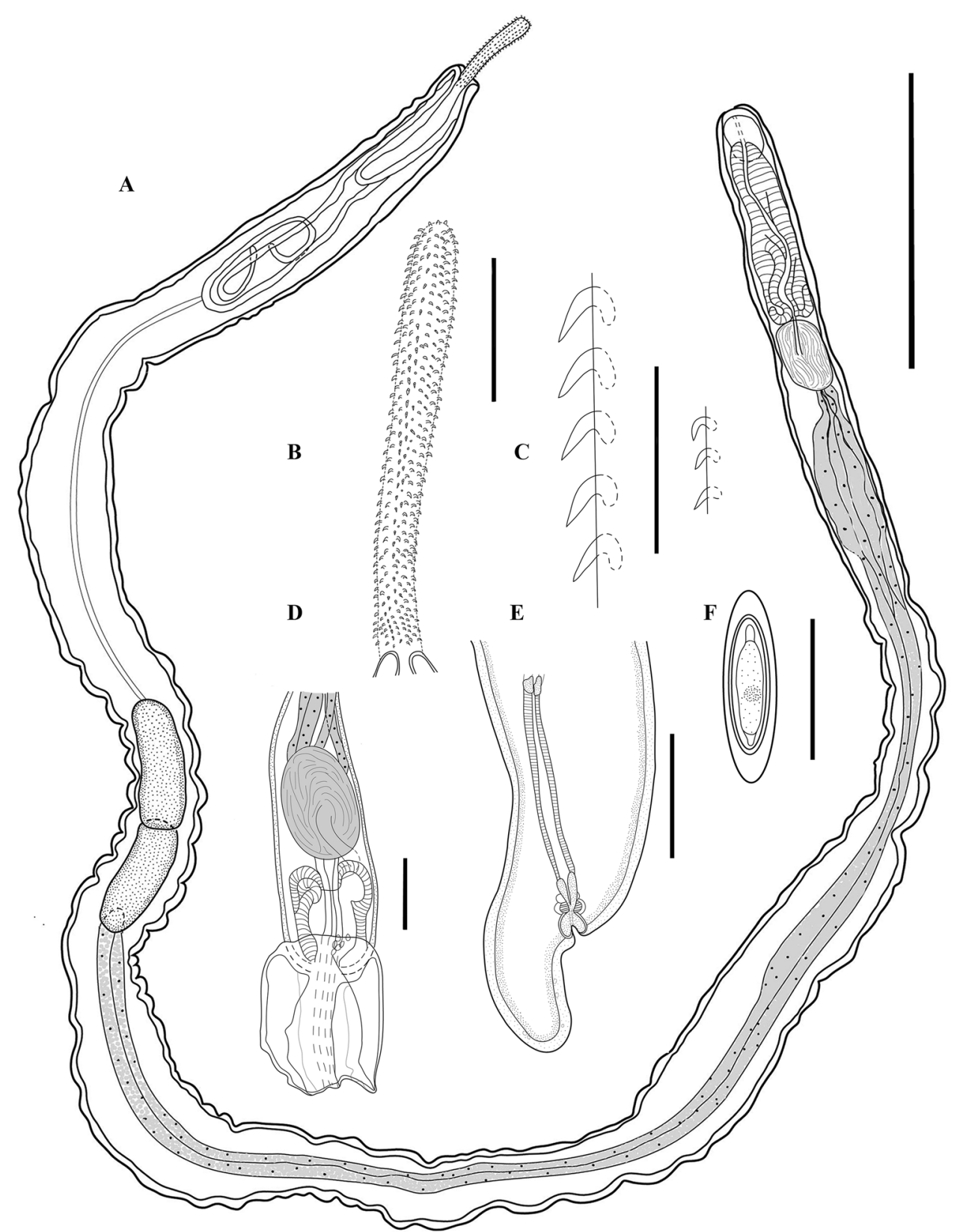


Fig. 2 Filisoma caudata n. sp. scanning electron microscopy micrographs. A Anterior end showing proboscis with hooks. B Hooks in detail. C Male posterior end. D Female posterior end
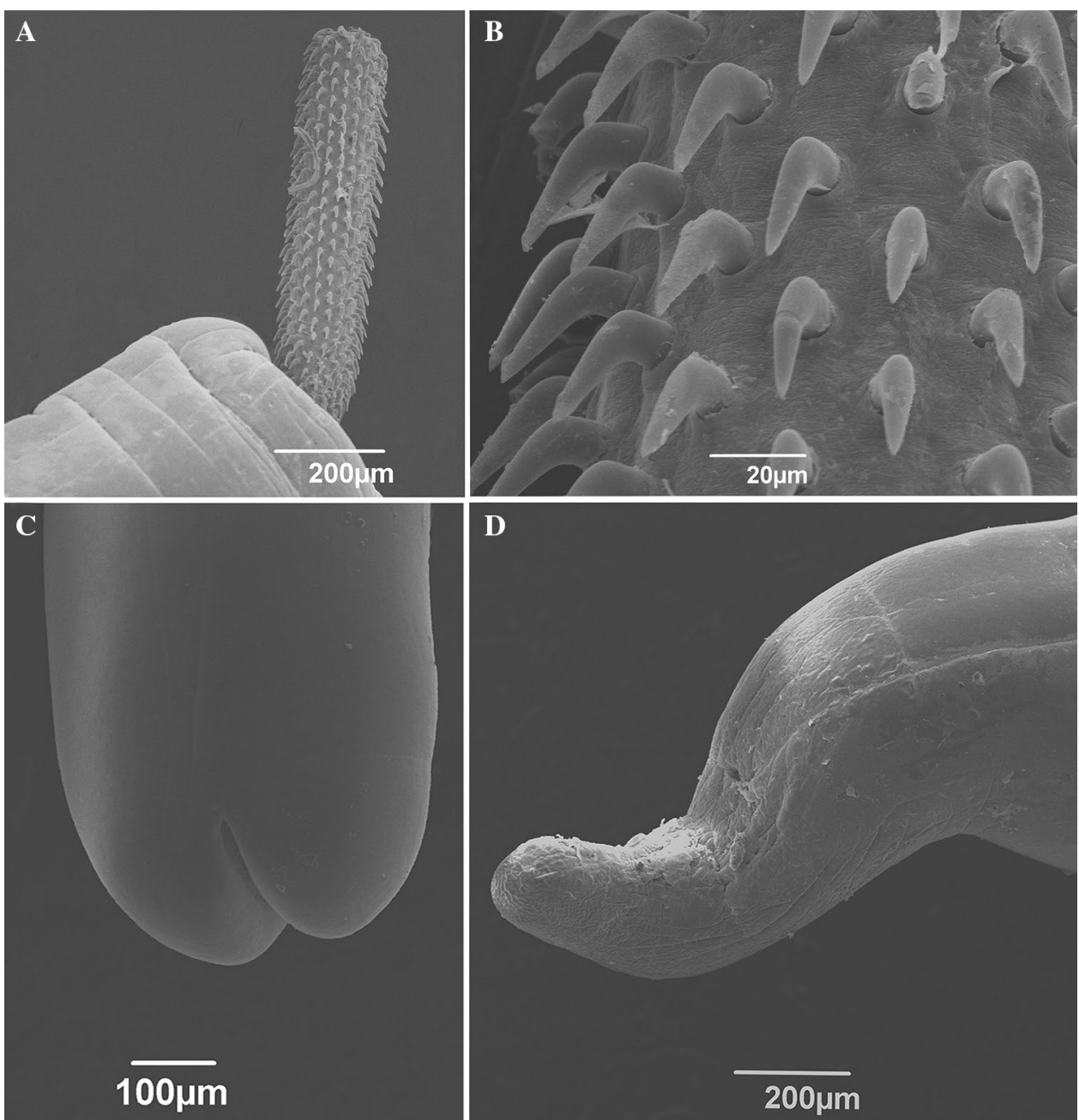

(30-35) long at middle, and $25(20-30)$ long posteriorly (Figs. 1A-C, 2A, B). Proboscis receptacle double walled with cerebral ganglion at its base. Lemnisci long, slender, subequal.

Males (based on 12 mature adults from both host species). Trunk 31 (25-37) [26] mm $\times 1.15$ (1.0-1.7) [1.0] mm. Proboscis $993(490-1210)$ [970] $\times 134(100-155)$ [120], partially everted, with 38-42 hooks per row. Proboscis receptacle double-walled, 1498 (1080-1790) [1080]. Neck 154 $(120-225)[120] \times 96(70-125)$ [110]. Cerebral ganglion 51 $(40-85)$ [40] $\times 84(60-135)$ [65]. Lemnisci, 5.0-6.50 and 7.3-7.5 mm long. Testes contiguous, pre-equatorial; anterior testis $1666(1200-2450)$ [1350] $\times 527(310-930)$ [450]. Posterior testis $1538(920-2420)$ [1500] ×498 (320-760) [450] (Fig. 1A). Four tubular cement glands about half as long as trunk, $14.6(11-16.8)$ [15.8] mm long, with small oval nuclei. Safftigen's pouch oval just anterior to copulatory bursa (Fig. 1D, invaginated in Fig. 2C).

Females (based on 12 gravid females from both host species). Trunk $52(39-65) \mathrm{mm} \times 1.3(1.0-1.7) \mathrm{mm}$. Proboscis $1211(820-1600) \times 165(125-355)$ with $42(39-45)$ hooks per row. Neck $169(125-200) \times 124(90-175)$. Proboscis receptacle 1770 (1520-1950) long with cerebral ganglion at its base, $89(40-160) \times 109(60-145)$. Lemnisci 4.5-7.0 and 7.6-8.4 mm long. Reproductive system 2.67 (2.14-3.33) $\mathrm{mm}$ long with subterminal gonopore and curved posterior end (Figs. 1E, 2D). Eggs ovoid-elongate with polar prolongations of fertilization membrane, $57(30-70) \times 19$ (15-20) (Fig. 1F).

\section{DNA Sequences}

For the partial $18 \mathrm{~S}$ rDNA sequences of $F$. caudata $\mathrm{n}$. sp., the BLASTN results indicated $96 \%$ identity with $F$. bucerium (AF064814) considering a 70\% query cover and max score 741; Acanthocephalus lucii (Müller, 1777) (AY830152) with $97 \%$ identity, $66 \%$ query cover and max score $741 ; F$. rizalinum (JX014229) with 96\% identity, 70\% query cover and max score 737; Acanthocephalus dirus (Van Cleave, 1924) (AY830151) with 96\% identity, 68\% query cover and 730 max score; and Acanthocephalus sp. (DQ147605) with 97\% identity, $66 \%$ query cover and max score 717 . 
For 28S rDNA gene (biggest sequence MH004455), the most similar sequences included those of Acanthocephalus nanus Van Cleave, 1925 (LC100043) with a 78\% identity, $99 \%$ query cover and a max score of 571 , A. lucii with $77 \%$ identity, 99\% query cover and a max score of 536, Pseudoacanthocephalus nguyenthileae Amin, Ha \& Heckmann, 2008 (KC491890), and Pseudoacanthocephalus buffonis (Shipley, 1903) (KC491878), both with a $79 \%$ identity, $88 \%$ query cover and a max score of 527 and 524, respectively.

For $\operatorname{cox}-1$ (accession number MH004408), the BLASTN results indicated for A. dirus (DQ089718) a 70\% identity, $84 \%$ query cover and a max score of 230, Echinorhynchida sp. Southwell \& Macfie, 1925 (EU732663) 68\% identity, $95 \%$ query cover and a max score of 224 and for both Bolbosoma caenoforme Heitz, 1920 (KF156891) and Bolbosoma sp. Porta, 1908 (JX442190), 68\% identity, 94\% query cover and a max score of 212 .

\section{Phylogenetic Analysis}

The phylogenetic reconstruction based on the partial sequence spanning the $18 \mathrm{~S}$ rDNA shows that our consensus sequence of $F$. caudata n. sp. is grouped with $F$. bucerium (AF064814) forming with $F$. rizalinum (JX14229) a clade of the family Cavisomidae. The sister clade with 54\% support is formed by species of Acanthocephalus. A major clade with $99 \%$ of support encloses the two former clades and Pseudacanthocephalus Petrochenko, 1958 species (Fig. 3). The paraphyletic Echinorhynchidae Cobbold, 1879 family is separated between the two major clades, with species of Echinorhynchus Zoega in Müller, 1776 clustering with species of Rhadinorhynchidae Travassos, 1923 and Pomphorhynchidae Yamaguti, 1939 with 79\% support, while the other genera grouped with Cavisomidae (Fig. 3).

On the partial 28S rDNA ML tree, our sequences of $F$. caudata n. sp. are grouped with $F$. bucerium (AY829110) with a statistical support of $85 \%$ in a clade of the family Cavisomidae, separated from two Echinorhynchidae clades, one formed by the species of Acanthocephalus and Pseudoacanthocephalus and the other with species of Echinorhynchus (Fig. 4).

On the ML reconstruction for the partial region of the mtDNA-cox 1 , all sequences of $F$. caudata clustered together with $100 \%$ of bootstrap support. The species of the genus Acanthocephalus appear as a sister group of our $F$. caudata. F. bucerium (DQ089722) is placed outside this cluster and shares a common ancestor with the cluster $F$. caudata + Acanthocephalus spp. Genus Echinorhynchus and Rhadinorhynchus Lühe, 1911 are placed in another cluster as sister groups with $80 \%$ of bootstrap support (Fig. 5).

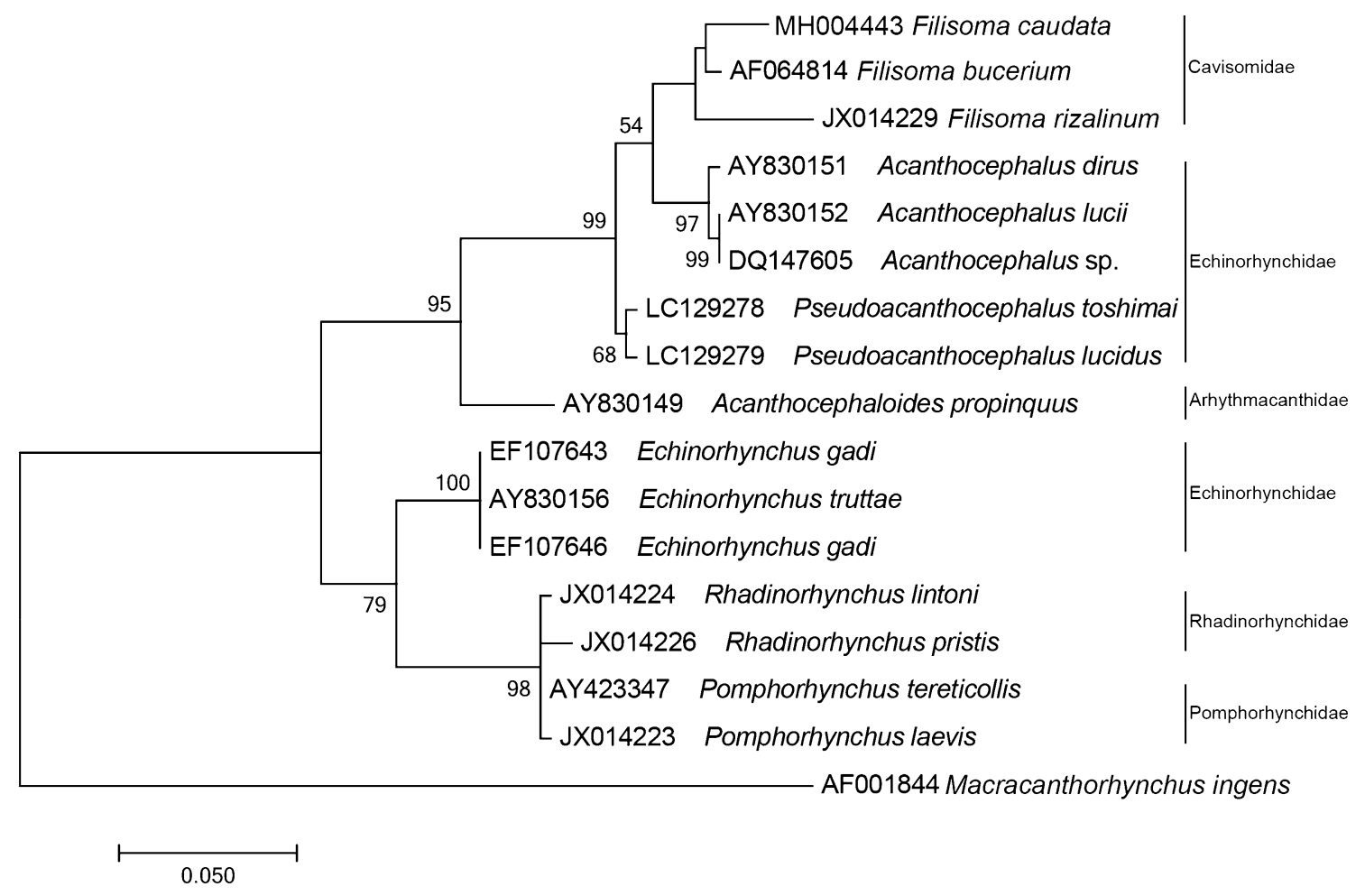

Fig. 3 Phylogenetic reconstruction based on the Maximum likelihood analysis using $18 \mathrm{~S}$ rDNA sequences of Filisoma caudata $\mathrm{n}$. sp. of this work and sequences of Acanthocephala deposited in the GenBank.
The numbers indicate values of bootstrap $>50 \%$. Macracanthorhyncus ingens is used as an outgroup 
Fig. 4 Phylogenetic reconstruction based on the Maximum likelihood analysis using $28 \mathrm{~S}$ rDNA sequences of Filisoma caudata $\mathrm{n}$. sp. of this work and sequences of Acanthocephala deposited in the GenBank. The numbers indicate that values of bootstrap $>50 \%$. Polyacanthorhynchus caballeroi are used as an outgroup

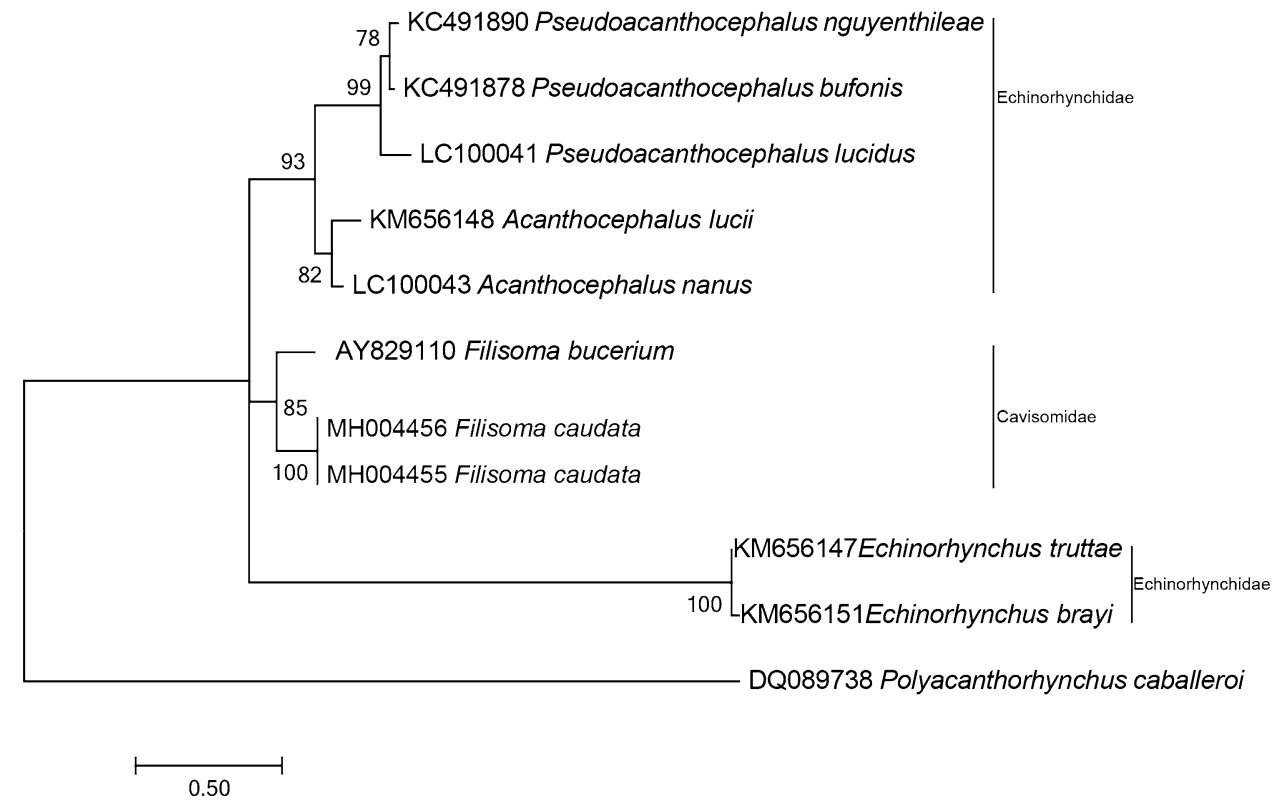

DQ089722 Filisoma bucerium

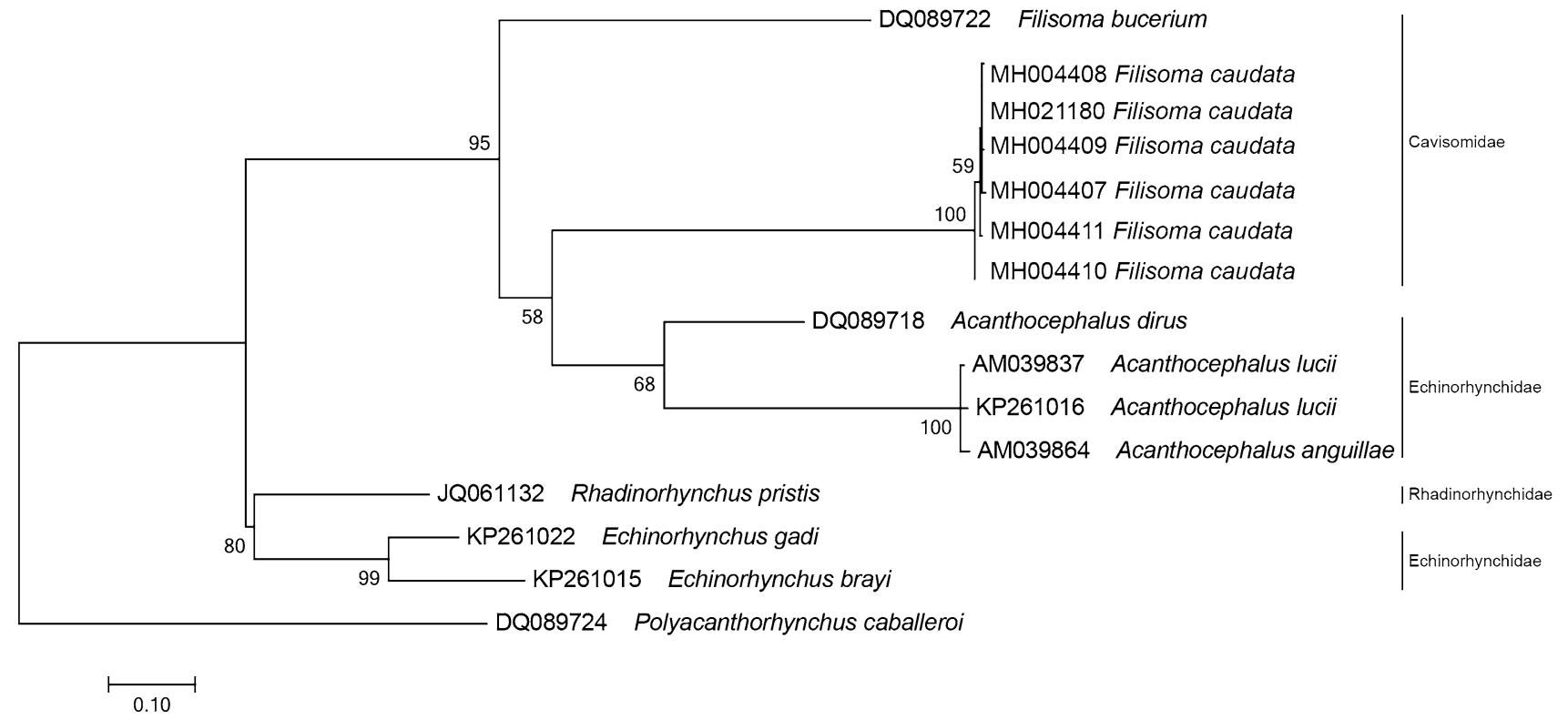

Fig. 5 Phylogenetic reconstruction based on the Maximum likelihood analysis using partial region of the mtDNA-cox-1 sequences of Filisoma caudata $\mathrm{n}$. sp. of this work and sequences of Acanthocephala

deposited in the GenBank. The numbers indicate that values of bootstrap $>50 \%$. Polyacanthorhynchus caballeroi are used as an outgroup

\section{Remarks}

Filisoma caudata n. sp. is differentiated from the closest species $F$. filiformis by the number of hooks (38-45 hooks vs 42-48), proboscis receptacle of males (1080-1790 vs 2499-3853), and a female genital pore (subterminal with a curved posterior end measuring 500-1000 long vs terminal pore), apart from hosts and geographical distribution (Atlantic vs. Pacific Ocean). A key to the 13 species of Filisoma Van Cleave, 1928 is provided below. 


\section{Key to the Species of Filisoma Parasites of Fish of the World}

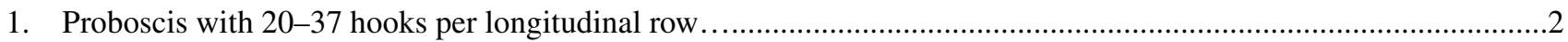

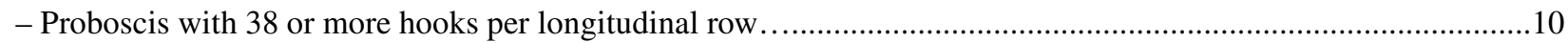

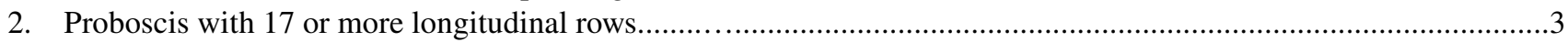

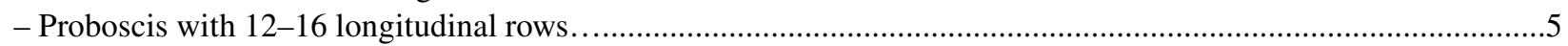

3. Proboscis with 17-18 longitudinal rows, with hooks uniform in shape and distribution........................................

- Proboscis with 17-19 longitudinal rows, 2 ventral rows with hooks more robust than hooks on dorsal rows, 25-26 hooks per row, lemnisci shorter than receptacle and long cement glands (3.56-16.02 mm), in Scatophagus argus (L. 1766) in Fiji Islands. Filisoma longcementglandatus

4. Proboscis with 18 longitudinal rows and 20 hooks per row, receptacle $1.84-2.4 \mathrm{~mm}$ long, lemnisci almost the same length of receptacle, in Acanthocybium solandri (Curvier, 1832) from China. Filisoma acanthocybii - Proboscis with 17-18 rows and 23-24 hooks per row, receptacle up to $1.01 \mathrm{~mm}$ long, lemnisci longer than proboscis receptacle and short cement glands (up to $2 \mathrm{~mm}$ ), in Saurus myops (Forster, 1801) from India.

Filisoma inglisi

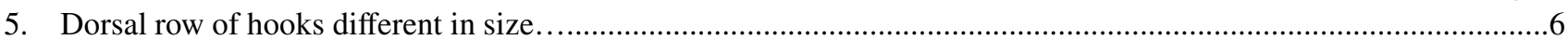

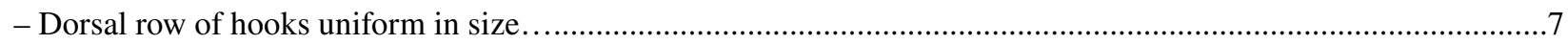

6. Proboscis $0.8-0.95 \mathrm{~mm}$ long with 16 longitudinal rows of $23-24$ hooks each, two submedian dorsal rows of hooks larger, trunk 23-27.5 mm, in S. argus from Philippines. Filisoma rizalinum - Proboscis $1.1 \mathrm{~mm}$ long with 14-16 longitudinal rows of 26-32 hooks each, dorsal hooks thicker and less pointed than ventral hooks, trunk $115 \mathrm{~mm}$, in S. argus from India... Filisoma scatophagusi

7. Proboscis with 12-14 longitudinal rows. 8 - Proboscis with 16 longitudinal rows, 28 hooks per row uniform in shape and leminisci shorter than proboscis receptacle, in Microcanthus strigatus (Curvier, 1831) from Taiwan. .Filisoma microcanthi

8. Without two ventral protuberances at vulva. . .9 - With two ventral protuberances at vulva, 24-28 hooks per row, body $20-30 \mathrm{~mm}$, receptacle $1.3 \mathrm{~mm}$ long and leminisci the same length of proboscis receptacle, in $S$. argus from India. Filisoma indicum

9. Trunk $7.5 \mathrm{~mm}$, proboscis $1.76 \mathrm{~mm}$ long with 14 longitudinal rows each with 28 hooks per row, parasitizes Oplegnathus fasciatus (Temminck \& Schlegel, 1844) from China. Filisoma oplegnathi - Trunk 8-8.4 mm, proboscis 1.14 long with 14 longitudinal rows each with 22 hooks per row; in Atropus atropos (Bloch \& Schneider, 1801) from China...... Filisoma atropi

10. Proboscis without 4 to 5 basal hooks configured in spiral.... . .11

- Proboscis with 4 to 5 basal hooks configured in spiral, 17-20 rows, 38 hooks per row, body 76-95 mm, receptacle up to $2.8 \mathrm{~mm}$ and leminisci shorter than proboscis receptacle, parasitize Kyphosus sectatrix from USA.

Filisoma fidum

11. Median dorsal longitudinal row of proboscis uniform

- Median dorsal longitudinal row of proboscis with blunt, hornlike hooks, proboscis 1.5-2.0 mm long with 16 longitudinal rows, 38-48 hooks per longitudinal row, body $45-60 \mathrm{~mm}$, receptacle up to $4.2 \mathrm{~mm}$ and leminisci with the same length of proboscis receptacle, parasitize Kyphosus elegans (Peters, 1869) from Mexico. .Filisoma bucerium

12. Proboscis 1.01-1.54 mm long with 16-18 longitudinal rows, 42-48 hooks per row, body $28-70 \mathrm{~mm}$, receptacle with 2.49-3.63 mm, leminisci longer than proboscis receptacle and female genital pore terminal, parasitize Kyphosus bigibbus Lacepède, 1801 and Kyphosus vaigiensis (Quoy \& Gaimard, 1825) from Austra lia......

Filisoma filiformis

- Proboscis 0.49-1.21 mm long with 16-18 longitudinal rows, 38-45 hooks per row, body 25-65 mm, receptacle with 1.08-1.95, leminisci longer than proboscis receptacle and female genital pore subterminal with posterior body end curved 500-1,000 long tail, parasitize Kyphosus incisor and Kyphosus sectatrix from Brasil.......

Filisoma caudata n. sp. 


\section{Discussion}

Four species of Filisoma parasitize kyphosid fish each of which has more than 28 proboscis hooks per longitudinal row: (1) F. filiformis from Kyphosus bigibbus, Kyphosus sydneyanus Günther, 1886 and Kyphosus vaigiensis off Australia, (2) F. bucerium from Kyphosus elegans off the Pacific coast of México, (3) F. fidum Van Cleave \& Manter, 1947 from $K$. sectatrix off the Atlantic coast of Florida, United States $[1,2,5,6]$ and (4) F. microcanthi from Microcanthus strigatus from Taiwan [22]. F. caudata n. sp. differs from $F$. filiformis by the subventral female gonopore followed by long posterior end (tail) and by the smaller difference in the number of hooks, as well as host and geographical distribution. F. bucerium can be primarily differentiated from the new species by having heavy and blunt modified dorsal hooks at middle of proboscis, lemnisci about the same length of receptacle and different shapes of the female tail $[1,6]$. $F$. fidum, although sharing the same host species with $F$. caudata n. sp., occurs far apart in the north Atlantic ocean (Florida) and can be differentiated by their larger size of males $(76 \times 25-37 \mathrm{~mm})$ and females $(95 \times 39-65 \mathrm{~mm})$, longer proboscis receptacle (up to $2.8 \mathrm{~mm}$ ) and longer testis $(3.5 \times 1.6 \mathrm{~mm})$. The absence of a long female tail can also be an inferred difference, considering that this character was not mentioned in the original description. The above key further differentiates our new species from these four species and others of the genus from other host species.

The phylogenetic analysis of the 28S rDNA sequences (Fig. 4) grouped $F$. caudata n. sp. with $F$. bucerium (AY829110) forming a clade of the family Cavisomidae between two clades in the family Echinorhynchidae confirming that different genera of Echinorhynchidae are paraphyletic [23-25]. Our phylogenetic tree for 28S rDNA is similar to those of Braincovich et al. [26] and Gárcia-Varela and Nadler [23], where the family Cavisomidae grouped close to the Echinorhynchidae genus Acanthocephalus. Although García-Varela and Nadler [23] commented that the 28S rDNA is not the most appropriate for taxonomic studies at the generic level, the 18S rDNA sequences appear to be more suitable to infer phylogenies among Acanthocephalans. The clade with the Cavisomidae had a good statistical support for the genus Filisoma. The phylogenetic analysis of the $18 \mathrm{~S}$ rDNA sequences (Fig. 3) confirmed a clade of Cavisomidae with $F$. caudata n. sp. and F. bucerium (AF064814) that are well separated from Echinorhynchidae, Arhythmacanthidae (see Braincovich [26]), Rhadinorhynchidae, and Pomphorhynchidae.

Our phylogenetic analysis of the mtDNA cox- 1 gene (Fig. 5) also grouped Filisoma spp. as sister groups of Acanthocephalus spp. However, more sequences of other species of Cavisomidae are necessary to better understand the relationship between species of these two genera, since Filisoma is the only genus with sequences available in the GenBank. Benesh et al. [27] discussed the reliability of the use of mitochondrial DNA amplified with universal primers for taxonomy since amplification could result in fragments of nuclear pseudogenes that have sequences similar to mitochondrial genes. In this work, the results of the phylogeny did not differ much in topology from the analysis made with nuclear genes indicating that the mitochondrial sequences used are reliable to infer phylogenies. The greater impediment to robust analysis was the reduced number of sequences deposited for the family Cavisomidae in the GenBank.

Amin [3] discussed the need of reevaluation of the families of Palaeacantocephala considering that the classification of families based only on morphology, e.g., the number of cement glands, can be doubtful. After Braincovich et al. [26] families with these characteristics may not be related as Cavisomidae and Rhadinorhynchidae, both usually with four cement glands that are grouped into different clades. Gymnorhadinorhynchidae Braicovich et al., 2014, for example, with four cement glands, group with Transvenidae Pichelin \& Cribb, 2001, which has only two cement glands [26].

The molecular data analyzed also suggest that families of Palaeacanthocephala must be reevaluated, since the delineation of monophyletic families was not clear in any of the topologies obtained, especially for species of Echinorhynchidae. The lack of sequences of different genera of Acanthocephala demonstrates that the use of molecular tools in defining species of Acanthocephala is still scarce and a large number of studies still describe and redescribe species based only on morphology [2, 4, 28-32]. For Cavisomidae, for example, there are genetic sequences of only three species available in the GenBank, all of them from the genus Filisoma (F. bucerium, F. rizalinum and now F. caudata $\mathrm{n}$. sp.). Therefore, new integrative studies with morphological, molecular and geographical distribution data help to determine species with reliability and are necessary to better understand the classification of acanthocephalans [23, 25]. Keys to species of Filisoma were previously provided by Van Cleave and Manter [1], Amin and Nahhas [5] and Weaver and Smales [2]. An updated key for species of Filisoma including $F$. caudata $\mathrm{n}$. sp. is now provided.

Acknowledgements This study was supported financially by the Conselho Nacional de Desenvolvimento Científico e Tecnológico (CNPqUniversal nos. 449658/2014-7 and 440410/2015-0), Fundação Oswaldo Cruz (PAEF IOC-008 FIO-04) and by the Coordenação de Aperfeiçoamento de Pessoal de Nível Superior-Brasil (CAPES-Finance code 001). C.P. Santos was sponsored by CNPq fellowship. The authors are grateful to Karina Corrêa Lopes, Ana Carolina Alves de Camargo and Lucas Keidel for technical support.

Author contributions VCF, JNB and CPS conceived and designed the study. VCF collected the specimens and performed the morphological 
and ultrastructural analysis. JNB performed molecular analysis. OMA developed and revised the manuscript. All authors wrote the paper and approved the final version of the manuscript. This study is part of the Master dissertation of VCF at the Postgraduate course in Biodiversity and Health at Institute Oswaldo Cruz, Fiocruz, Brasil.

OpenAccess This article is distributed under the terms of the Creative Commons Attribution 4.0 International License (http://creativeco mmons.org/licenses/by/4.0/), which permits unrestricted use, distribution, and reproduction in any medium, provided you give appropriate credit to the original author(s) and the source, provide a link to the Creative Commons license, and indicate if changes were made.

\section{References}

1. Van Cleave, H.J., Manter, H.W. 1947. A new species of the acanthocephalan genus Filisoma from the Dry Tortugas, Florida. Journal of Parasitology, 33, 487-90. https://doi.org/10.2307/3273329.

2. Weaver, H.J., Smales, L.R. 2013. Filisoma filiformis n. sp. (Echinorhynchida: Cavisomidae), a New Species of Acanthocephala from Kyphosus spp. Perciformes: Kyphosidae) from the South Pacific, and a Key to the Genus Filisoma. Comparative Parasitology, 80, 33-8. https://doi.org/10.1654/4571.1.

3. Amin, O.M. 2013. Classification of Acanthocephala. Folia Parasitologica, 60, 273-305. https://doi.org/10.14411/fp.2013.031.

4. Amin, O.M., Heckmann, R.A., Van Ha N. 2014. Acanthocephalans from fishes and amphibians in Vietnam, with descriptions of five new species. Parasite, 21, 1-17. https://doi.org/10.1051/ parasite/2014052

5. Amin, O.M., Nahhas, F.M. 1994. Acanthocephala of marine fishes off Fiji Islands, with descriptions of Filisoma longcementglandulatus n. sp. (Cavisomidae), and gravid females of Rhadinorhynchus johnstoni (Rhadinorhynchidae); and Keys to species of the genera Filisoma and Neorhadinorhynchus. Journal of Parasitology, 80, 768-74.

6. Léon-Règagnon, V., Pérez-Ponce de León, G., Garcia-Prieto, L. 1997. Description of Heteroplectanum oliveri n.sp. (Monogenea: Diplectanidae) and comments on the helminth fauna of Kyphosus elegans (Perciformes: Kyphosidae) from Chamela Bay, México. Proceedings of the Helminthological Society of Washington, 64, 9-16.

7. Manter, H.W. 1965. Parasites of fishes as biological indicators of recent and ancient conditions. In: Proceedings of the XXVI Annual Biology Colloquium: Host-parasite relationships (Ed J. E. McCauley). Oregon State University Press, Corvallis, pp. 59-71.

8. Pérez-Ponce de León, G., García-Prieto, L., Mendonza-Garfias, B. 2011. Describing Parasite Biodiversity: The Case of the Helminth Fauna of Wildlife Vertebrates in Mexico. In: (Eds O. Grillo, and G. Venora) Diversity in Changing Environment. InTech, Rijeka, p. 392.

9. Dayrat, B. 2005. Towards integrative taxonomy. Biological Journal of the Linnean Society, 85, 407-415. https://doi.org/10.111 1/j.1095-8312.2005.00503.x.

10. Padial, J.M., Miralles, A., De La Riva, I., Vences, M. 2010. The integrative future of taxonomy. Frontiers in zoology, 7, 1-16. https ://doi.org/10.1186/1742-9994-7-16.

11. Froese, R., Pauly, D. 2017. FishBase. World Wide Web electronic publication. http://www.fishbase.org, version (07/2017).

12. Coleman, C.O. 2003. "Digital inking": How to make perfect line drawings on computers. Organisms Diversity \& Evolution, 14, 1-14. https://doi.org/10.1078/1439-6092-00081.
13. Bush, A.O., Lafferty, K.D., Lotz, J.M., Shostak, A.W. 1997. Parasitology meets ecology on its own terms: Margolis et al. revisited. Journal of Parasitology, 83, 575-83. https://doi. org/10.2307/3284227.

14. Billings, A.N., Teltow, G.J., Weaver, S.C., Walker, D.H. 1998. Molecular characterization of a novel Rickettsia species from Ixodes scapularis in Texas. Emerging Infectious Diseases, 4 , 305-9. https://doi.org/10.3201/eid0402.980221.

15. Hassouna, N., Michot, B., Bachellerie, J.P. 1984. The complete nucleotide sequence of mouse $28 \mathrm{~S}$ rRNA gene. Implications for the process of size increase of the large subunit rRNA in higher eukaryotes. Nucleic Acids Research, 12, 3563-3583. https://doi. org/10.1093/nar/12.8.3563.

16. Chisholm, L.A., Whittington, I.D., Morgan, J.A.T., Adlard, R.D. 2001. The Calicotyle conundrum: do molecules reveal more than morphology? Systematic Parasitology, 49, 81-7. https://doi. org/10.1023/a:1010629022955.

17. Sinnappah, N.D., Lim, L.H.S., Rohde, K., Tinsley, R., Combes, C., Verneau, O. 2001. A pleomorphic parasite associated with a neotenic amphibian host: phylogenetic evidence suggests a revised systematic position for Sphyranuridae within anuran and turtle polystomatoineans. Molecular Phylogenetics and Evolution, 18, 189-201. https://doi.org/10.1006/mpev.2000.0877.

18. Folmer, O., Black, M., Hoeh, W., Lutz, R., Vrijenhoek, R. 1994. DNA primers for amplification of mitochondrial cytochrome $c$ oxidase subunit I from diverse metazoan invertebrates. Molecular Marine Biology and Biotechnology, 3, 294-299.

19. Kumar, S., Stecher, G., Tamura, K. 2015. MEGA7: Molecular Evolutionary Genetics Analysis version 7.0. Molecular Biology and Evolution, 33, 1870-1874. https://doi.org/10.1093/molbev/ msw054.

20. Altschul, S.F., Gish, W., Miller, W., Myers, E.W., Lipman, D.J. 1990. Basic Local Alignment Search Tool. Journal of Molecular Biology, 215, 403-10. https://doi.org/10.1016/s0022 -2836(05)80360-2.

21. Thompson, J.D., Higgins, D.G., Gibson, T.J. 1994. CLUSTAL $\mathrm{W}$ : improving the sensitivity of progressive multiple sequence alignment through sequence weighting, position-specific gap penalties and weight matrix choice. Nucleic Acids Research, 22, 4673-4680. https://doi.org/10.1007/978-1-4020-6754-9.

22. Harada, I. 1938. Acanthocephalen aus Formosa. Anotationes Zoologicae Japonenses, 17, 419-427. (In German).

23. García-Varela, M., Nadler, S.A. 2005. Phylogenetic relationships of Palaeacanthocephala (Acanthocephala) inferred from SSU and LSU rDNA gene sequences. Journal of Parasitology, 91, 1401-9. https://doi.org/10.1645/ge-523r.1.

24. Monks, S. 2001. Phylogeny of the Acanthocephala based on morphological characters. Systematic Parasitology, 48, 81-116. https ://doi.org/10.1023/a:1006400207434.

25. Verweyen, L., Klimpel, K., Palm, H.W. 2011. Molecular Phylogeny of the Acanthocephala (Class Palaeacanthocephala) with a Paraphyletic Assemblage of the Orders Polymorphida and Echinorhynchida. Plos One, 6, 1-9. https://doi.org/10.1371/journ al.pone.0028285.

26. Braincovich, P., Lanfranchi, A.L., Farber, M.D., Marvaldi, A.E., Luque, J.L., Timi, J.T. 2014. Genetic and morphological evidence reveals the existence of a new family, genus and species of Echinorhynchida (Acanthocephala). Folia Parasitologica, 61, 377-84. https://doi.org/10.14411/fp.2014.044.

27. Benesh, D.P., Hasu, T., Suomalainen, L-R., Valtonen, E.T., Tiirola, M. 2006. Reliability of mitochondrial DNA in an acanthocephalan: The problem of pseudogenes. International Journal for Parasitology, 36, 247-254. https://doi.org/10.1016/j.ijpar a.2005.09.008. 
28. Amin, O.M., Gholami, Z., Akhlaghi, M., Heckmann R.A. 2013. The Description and Host-Parasite Relationships of a New Quadrigyrid Species (Acanthocephala) from the Persian Tooth-Carp, Aphanius farsicus (Actinoptreygii: Cyprinodontidae) in Iran. Journal of Parasitology, 99, 257-263. https://doi.org/10.1645/ ge-3247.1.

29. Gomes, A.P.N., Olifiers, N., Souza, J.G.R., Barbosa, H.S., D’Andrea, P.S., Maldonado Jr, A. 2015. A new acanthocephalan species (Archiacanthocephala: Oligacanthorhynchidae) from the crab-eating fox (Cerdocyon thous) in the Brazilian Pantanal wetlands. Journal of Parasitology, 101, 74-79. https://doi. org/10.1645/13-321.1.

30. Salgado-Maldonado, G. 2013. Redescription of Neoechinorhynchus (Neoechinorhynchus) golvani Salgado-Maldonado, 1978
(Acanthocephala: Neoechinorhynchidae) and description of a new species from freshwater cichlids (Teleostei: Cichlidae) in Mexico. Parasitology Research, 112, 1891-1901. https://doi.org/10.1007/ s00436-013-3374-7.

31. Smales, L.R. 2014. The genus Rhadinorhynchus (Acanthocephala: Rhadinorhynchidae) from marine fish in Australia with the description of four new species. Acta Parasitologica, 59, 721-736. https://doi.org/10.2478/s11686-014-0305-4.

32. Steinauer, M.L., Nickol, B.B. 2015. Revision of Leptorhynchoides thecatus (Acanthocephala: Illiosentidae), with Morphometric Analysis and Description of Six New Species. Journal of Parasitology, 101, 193-211. https://doi.org/10.1645/14-644.1.

Publisher's Note Springer Nature remains neutral with regard to jurisdictional claims in published maps and institutional affiliations.

\section{Affiliations}

\section{Viviane S. Costa Fernandes ${ }^{1} \cdot$ Omar Amin ${ }^{2} \cdot$ Juliana N. Borges ${ }^{1} \cdot$ Cláudia P. Santos $^{1}$}

Viviane S. Costa Fernandes

vivianes.costa@yahoo.com.br

Omar Amin

omaramin@aol.com

Juliana N. Borges

juliananovo@bol.com.br
1 Laboratório de Avaliação e Promoção da Saúde Ambiental (LAPSA)-Fundação Oswaldo Cruz, Av. Brasil 4365, Rio de Janeiro 21040-360, Brazil

2 Institute of Parasitic Diseases, Scottsdale, AZ, USA 